\title{
Evaluating the impact of morning symptoms in COPD using the Capacity of Daily Living during the Morning (CDLM) questionnaire
}

This article was published in the following Dove Press journal: International Journal of COPD

\author{
Alexa Núñez' \\ Cristina Esquinas' \\ Miriam Barrecheguren' \\ Myriam Calle ${ }^{2,3}$ \\ Ricard Casamor ${ }^{4}$ \\ Marc Miravitlles ${ }^{1,5}$ \\ 'Pneumology Department, Hospital \\ Universitari Vall d'Hebron/Vall \\ d'Hebron Institut de Recerca (VHIR), \\ Barcelona, Spain; ${ }^{2}$ Pneumology \\ Department, Hospital Clínico de San \\ Carlos, Madrid, Spain; ${ }^{3}$ Departamento \\ de Medicina, Facultad de Medicina, \\ Universidad Complutense de Madrid, \\ Madrid, Spain; ${ }^{4}$ Medical Department, \\ Novartis Farmaceutica, Barcelona, \\ Spain; ${ }^{5} \mathrm{CIBER}$ de Enfermedades \\ Respiratorias (CIBERES), Barcelona, \\ Spain
}

Correspondence: Marc Miravitlles Pneumology Department, Hospital Universitari Vall d'Hebron/Vall d'Hebron Institut de Recerca (VHIR), P. Vall d'Hebron I19-129, 08035 Barcelona, Spain

Tel +34934893000

Fax+34932748208

Email mmiravitlles@vhebron.net
Purpose: The aim of this study was to evaluate the impact of morning symptoms in COPD using the Capacity of Daily Living during the Morning (CDLM) questionnaire and to determine the clinical variables that are related to CDLM scores.

Methods: This was an observational, cross-sectional, and multicenter study conducted in stable COPD patients. CDLM scores ranged from 0 to 5 and were transformed into a qualitative variable according to tertile values to compare patient characteristics. A multivariate linear regression model was used to identify the clinical variables related to CDLM scores.

Results: A total of 605 patients were included in the study; the mean age (SD) was 68 years (9.1) and mostly were male (80.8\%). The mean post-bronchodilator $\mathrm{FEV}_{1} \%$ was $53.4 \%$ (19.2\%), and the mean BODEx (body mass index, airway obstruction, dyspnea, exacerbation) score was 3.2 (2.0). The mean COPD assessment test (CAT) score was $16.6(8.3)$, and the mean CDLM score was $4.2(0.9)$. First tertile patients, that is, those with a higher impact in the morning, were older, had more respiratory symptoms, more dyspnea, a lower $\mathrm{FEV}_{1} \%$, lower CAT and BODEx scores, and more exacerbations. We found a ceiling effect on the CDLM scores: 194 (32\%) patients scored 5.00 and no patients scored 0 . On multivariate analysis, higher CAT and BODEx scores, a lower $\mathrm{FEV}_{1} \%$, and use of long-term oxygen therapy (LTOT) were all independently related to lower CDLM scores.

Conclusion: Morning respiratory symptoms are associated with more severe airflow obstruction, lower CAT and BODEx scores, and LTOT. The ceiling effect of the CDLM questionnaire does not allow it to discriminate well between low and high impact of morning symptoms.

Keywords: health-related quality of life, COPD, morning symptoms questionnaire, CAT

\section{Introduction}

COPD is characterized by chronic airflow limitations and persistent symptoms and is mainly caused by tobacco smoking. COPD is a heterogeneous disease with variations in clinical presentation, response to treatment and prognosis. ${ }^{1}$

There is an increasing evidence that physiological parameters of lung function (inspiratory capacity, $\mathrm{FEV}_{1}, \mathrm{FVC}$, and peak expiratory flow) in patients with COPD vary greatly along the day. ${ }^{2-5}$ Similarly, diurnal COPD symptoms are variable, and COPD patients report morning as being the worst time of the day, with symptoms impacting their ability to perform routine morning activities (washing, drying, and dressing) and thereby affecting their health-related quality of life (HRQoL). ${ }^{6}$

Although morning seems to be the most burdensome time of the day for COPD patients, few tools have been developed to quantify the impact of morning symptoms in COPD. The Capacity of Daily Living during the Morning (CDLM) is a validated, 
self-administered questionnaire that measures the ability of patients to carry out six different morning activities. ${ }^{7}$ Two randomized clinical trials showed that the CDLM questionnaire has good-to-high reliability and correlates significantly with symptoms, HRQoL, and the use of rescue medication..$^{8-10}$

However, no studies have investigated the correlation of CDLM scores with other clinical variables and questionnaires frequently used in COPD outside the context of a clinical trial.

The aim of the present study was to determine the variables related to CDLM scores in a large population of patients with different degrees of functional impairment in both primary and secondary care.

\section{Methods}

\section{Study design}

The FENEPOC (Identification and distribution of COPD phenotypes in clinical practice according to Spanish COPD guidelines) study was an observational, cross-sectional, multicenter study, which aimed to determine the distribution of COPD phenotypes and evaluate the availability of diagnostic tools for the classification of COPD phenotypes.

A detailed description of the protocol has been published elsewhere. ${ }^{11}$ Here, we present the results of the evaluation of the CDLM questionnaire as a tool to measure the impact of COPD on morning activities.

\section{Participants}

The patients included were recruited from primary care and pulmonology centers in Spain from November 2012 to December 2013. The inclusion criteria were stable ambulatory COPD patients (at least 1 month following recovery from the last exacerbation); age $\geq 40$ years; current or former smoker with a smoking history of at least 10 pack-years and a post-bronchodilator forced spirometry $\mathrm{FEV}_{1} / \mathrm{FVC}$ ratio $<0.7$ or a pre-bronchodilator $\mathrm{FEV}_{1} / \mathrm{FVC}$ ratio $<0.7$ and $\mathrm{FEV}_{1}<80 \%$ (when a post-bronchodilator test was not available). The exclusion criteria were the presence of another chronic respiratory disease (eg, cystic fibrosis, severe bronchiectasis, cancer, or restrictive lung disease) and inability to complete the quality of life questionnaires.

\section{Ethics approval and informed consent}

All the procedures performed in this study were in accordance with ethical standards of the Institutional Review Board and with the Declaration of Helsinki. This study was approved by the Ethics Committee of Hospital Clínic i Provincial de
Barcelona, Spain. Written informed consent was obtained from all study participants.

\section{Variables}

The sociodemographic characteristics and clinical COPD data of the patients included were collected. The degree of dyspnea was assessed according to the modified Medical Research Council dyspnea scale. ${ }^{12}$ The BODEx (body mass index, airway obstruction, dyspnea, exacerbation) index was calculated. ${ }^{13}$ Other variables studied included lung function tests, clinical symptoms (cough, expectoration, wheezing), and number of exacerbations.

Patients were classified into the following clinical phenotypes according to the GesEPOC (Spanish COPD guidelines) criteria: ${ }^{14}$ 1) non-exacerbators $(\mathrm{NE})$ : patients with 0 or 1 exacerbation in the previous year; 2 ) exacerbators with emphysema (EE): patients with at least two exacerbations in the previous year and clinical/radiological or functional evidence of EE; 3) exacerbators with chronic bronchitis (ECB): exacerbators with cough and expectoration for at least 3 months of the year over 2 consecutive years; and 4) asthma-COPD overlap: patients who met two major criteria or one major and two minor criteria. Major criteria were previous history of asthma and bronchodilator response to salbutamol $>15 \%$ and $400 \mathrm{~mL}$, and minor criteria were high total IgE, history of atopy, two separate bronchodilator responses to salbutamol $>12 \%$ and $200 \mathrm{~mL}$, and blood eosinophil levels $>5 \%{ }^{15}$

Exacerbation was defined as an acute increase in respiratory symptoms requiring treatment with antibiotics and/or systemic corticosteroids or treatment in a hospital setting. ${ }^{11}$

\section{COPD Assessment Test (CAT) and CDLM} questionnaires

The CAT is a short questionnaire that consists of eight items that reflect symptom burden and limitations in patient activity due to COPD: cough, phlegm, chest tightness, breathlessness on going up hills or stairs, any limitation in activity at home, confidence leaving home, sleep, and energy. The scale ranges from 0 to 5 points for each item, and the total score ranges from 0 to 40 , with higher scores indicating a poorer perception of disease-related health status. A score of 2 points is considered as a minimum clinically important difference (MCID). ${ }^{16}$

Patients were also asked to answer the CDLM questionnaire, which is a self-administered test in which patients are required to report their ability to carry out six different 
morning activities and rank the difficulty of performing each activity in a 5-point Likert-type scale ranging from 0 (not difficult) to 4 (extremely difficult). The responses to the two questions for each morning activity are used to calculate a score ranging from 0 (so difficult that the activity could not be carried out by the patient on their own) to 5 (activity that was not at all difficult to carry out). There is no weighting of the different morning activities, and the total CDLM score was calculated as the average of all the morning activities. Higher scores in the CDLM questionnaire represent a better HRQoL. ${ }^{7}$

\section{Statistical methods}

The frequency and valid percentage of the qualitative variables were determined. Regarding the quantitative variables, measurements of central tendency and dispersion were used (mean and SD).

The CDLM score was transformed into a qualitative variable according to the tertile values in order to determine the variables related to the questionnaire. In the case of quantitative variables, comparisons of patient characteristics according to CDLM tertiles were carried out with the use of the ANOVA (Kruskal-Wallis if normality was not assumed) with linear trend analysis and Bonferroni correction for multiple comparisons. The chi-squared test (Fisher's exact test for frequencies $<5$ ) was employed for the comparison of categorical variables with the Kendall's tau linear trend test. Linear relationships were analyzed using Pearson correlations.

A multivariate analysis was performed using a back stepwise multinomial model in order to identify the variables related to the CDLM tertile scores. Relevant clinical variables with a $P$-value $<0.1$ in the univariate analysis with outcome were included as independent variables in the stepwise models.

Receiver operating characteristic curve analysis was used to analyze the predictive power of the CDLM score to detect characteristics reflecting COPD severity (BODEx $\geq 2$ and CAT $\geq 10$ ). For all the tests, a difference with a twotailed $P$-value $<0.05$ was determined to be significant. The statistical package SPSS (V 23) was used.

\section{Results}

\section{Participants}

A total of 647 patients with COPD meeting all the inclusion criteria were recruited; of these, 605 (93.5\%) had a valid CDLM questionnaire and constituted the population of our study.

\section{Descriptive data}

The global mean age (SD) was 68 years (9.1), and most patients were male $(80.8 \%)$. Seventy-three percent were former smokers with a mean tobacco consumption of 43.9 (23) pack-years. The mean post-bronchodilator $\mathrm{FEV}_{1} \%$ was $53.4 \%(19.2 \%)$, and the mean BODEx score was $3.2(2.0)$. The mean CAT score was 16.6 (8.3), and the mean CDLM score was 4.5 (interquartile range 3.8-5). The distribution of the tertiles of the CDLM scores provided the following thresholds: $<4.17,4.17-4.89,=5.00$. We found a ceiling effect on the distribution of the CDLM scores: of the 605 patients studied, 194 (32\%) had a CDLM score of 5.00 and no patient scored 0 . The lowest value registered was 0.67 . The sociodemographic and clinical characteristics for the entire sample and by tertile are shown in Table 1.

\section{Main results}

Sociodemographic and clinical characteristics according to CDLM tertiles

On comparing the different tertiles, we observed that patients in the first and second tertiles, that is, those having a higher impact in the morning, were older, albeit not significantly, than patients in the third tertile.

In comparison with patients in the third tertile, those in the first tertile had a higher grade of dyspnea $(2.3(0.8)$ vs 1.3 (0.8): $P<0.001$ ), a higher mean CAT score (23.4 (6.8) vs $10.7(6.2) ; P<0.001)$ and higher mean BODEx score (4.8 (2.2) vs $2.0(1.3) ; P<0.001)$, as well as a higher rate of moderate and severe exacerbations per year. In regard to treatment, patients in the first tertile more frequently used long-term oxygen therapy (LTOT) in contrast to patients in the third tertile. We did not find statistically significant differences between the first and third tertiles in the other variables studied.

However, we did find statistically significant differences between the first and second tertiles in terms of lung function impairment: $\mathrm{FEV}_{1}$ \% (48.7 (20.7) vs 50.9 (16), respectively; $P<0.001)$, exacerbations requiring hospitalization $(0.68$ (0.94) vs $0.44(0.83) ; P<0.001)$, and use of long-acting antimuscarinic agents $(92.5 \%$ vs $80.8 \% ; P=0.001)$ and inhaled corticosteroids $(69.3 \%$ vs $53.4 \% ; P<0.001)$ (Table 1$)$.

\section{CDLM score according to clinical phenotypes} and linear relationship between the CDLM score and COPD severity-related variables

Regarding clinical phenotypes, ECB was the most frequent phenotype among the first tertile compared to the second and third tertiles, in which the NE phenotype predominated. 
Table I Sociodemographic and clinical characteristics according to CDLM scores

\begin{tabular}{|c|c|c|c|c|c|}
\hline Variables & $\begin{array}{l}\text { Global } \\
N=605\end{array}$ & $\begin{array}{l}\text { TI } \\
n=199\end{array}$ & $\begin{array}{l}T 2 \\
n=2 \mid 2\end{array}$ & $\begin{array}{l}T 3 \\
n=194\end{array}$ & $P$-value \\
\hline Age, years & $68(9.1)^{* *}$ & $69.3(8.2)^{* *}$ & $68.9(9.7)^{* *}$ & $65.5(8.8)^{* *}$ & $<0.00^{\mathrm{b}, \mathrm{c}}$ \\
\hline Sex, male & $488(80.8 \%)$ & $163(82.3 \%)$ & 164 (77.4\%) & 161 (83\%) & 0.285 \\
\hline Active smokers & I7I (28.3\%) & $56(28.1 \%)$ & $56(26.4 \%)$ & 59 (30.4\%) & 0.670 \\
\hline Pack-years & $43.9(23.0)$ & $44.3(21.3)$ & $42(22.9)$ & $45.5(24.6)$ & 0.299 \\
\hline $\mathrm{BMI}, \mathrm{kg} / \mathrm{m}^{2}$ & $27.4(4.5)^{* *}$ & $27.2(4.8) * *$ & $27.7(4.6) * *$ & $27.4(4.2)^{* *}$ & 0.522 \\
\hline \multicolumn{6}{|l|}{ Symptoms } \\
\hline Chronic cough & $75 \%$ & $81.8 \%$ & $77.3 \%$ & $65.8 \%$ & $0.00 I^{b, c}$ \\
\hline Expectoration & $61.8 \%$ & $72.7 \%$ & $57.4 \%$ & $55.7 \%$ & $0.00 I^{a, b}$ \\
\hline Dyspnea & $88 \%$ & $96 \%$ & $92.5 \%$ & $75 \%$ & $<0.00 I^{b, c}$ \\
\hline Wheezing & $38.3 \%$ & $49.5 \%$ & $37.9 \%$ & $27.1 \%$ & $<0.00 \mathrm{I}^{\mathrm{b}}$ \\
\hline Dyspnea mMRC & $1.8(0.9)^{* *}$ & $2.3(0.8)^{* *}$ & $1.8(0.8)^{* *}$ & $1.3(0.8) * *$ & $<\left.0.00\right|^{a, b, c}$ \\
\hline $\mathrm{FVC}(\mathrm{mL})$ & $2,856(904)^{* *}$ & $2,564(802)^{* *}$ & $2,695(903)^{* *}$ & $2,906(866.7)^{* *}$ & $<0.00 \mathrm{I}^{\mathrm{b}, \mathrm{c}}$ \\
\hline FVC (\%) & $75.5(22)^{* *}$ & $70.7(20) * *$ & $73.2(18.4)^{* *}$ & $77.5(17.5)^{* *}$ & $<0.00 \mathrm{I}^{\mathrm{b}}$ \\
\hline $\mathrm{FEV}_{1}(\mathrm{~mL})$ & $\mathrm{I}, 520(577)^{* *}$ & $\mathrm{I}, 320(54 \mathrm{I})^{* *}$ & $\mathrm{I}, 395(54 \mathrm{I})^{* *}$ & $\mathrm{I}, 536 . \mathrm{I}(544)^{* *}$ & $<0.00 I^{b, c}$ \\
\hline $\mathrm{FEV}_{1}(\%)$ & $53.4(19.2)^{* *}$ & $48.7(20.7)^{* *}$ & $50.9(16)^{* *}$ & $53.9(15.7)^{\text {** }}$ & $<\left.0.00\right|^{a, b}$ \\
\hline \multicolumn{6}{|l|}{ GESEPOC phenotypes } \\
\hline Non-exacerbator & $316(52.6 \%)$ & $66(33.5 \%)$ & II 5 (54.5\%) & I 35 (69.9\%) & $<\left.0.00\right|^{a, b, c}$ \\
\hline $\mathrm{ACO}$ & $35(5.8 \%)$ & $13(6.6 \%)$ & II (5.2\%) & II (5.7\%) & 0.833 \\
\hline Exacerbator with emphysema & $70(11.6 \%)$ & $23(11.7 \%)$ & $31(14.3 \%)$ & $16(8.3 \%)$ & 0.134 \\
\hline Exacerbator with chronic bronchitis & $180(30 \%)$ & 95 (48.2\%) & $54(25.6 \%)$ & $31(16.1 \%)$ & $<0.00 I^{a, b}$ \\
\hline CAT score & $16.6(8.3)^{* *}$ & $23.3(6.8) * *$ & $15.7(6.5) * *$ & $10.7(6.2)^{* *}$ & $<\left.0.00\right|^{a, b, c}$ \\
\hline BODEx & $3.2(2.0)^{* *}$ & $4.8(2.2)^{* *}$ & $3.0(2.0)^{* *}$ & $2.0(1.3)^{* *}$ & $<\left.0.00\right|^{a, b, c}$ \\
\hline \multirow[t]{2}{*}{ CDLM score } & $4.2(0.9)^{* *}$ & $3.1(0.8)^{* *}$ & $4.5(0.2)^{* *}$ & $5(0.09)^{* *}$ & $<\left.0.00\right|^{a, b, c}$ \\
\hline & $4.5(3.8 ; 5)^{*}$ & $3.3(2.5 ; 3.8)^{*}$ & $4.5(4.3 ; 4.7)^{*}$ & $5(5 ; 5) *$ & \\
\hline Moderate/severe exacerbations last year & $1.8(1.8)^{* *}$ & $2.6(1.9)^{* *}$ & $1.7(1.6)^{* *}$ & $1.16(1.3)^{* *}$ & $<\left.0.00\right|^{a, b, c}$ \\
\hline Exacerbations requiring hospitalization last year & $0.5(0.8)^{* *}$ & $0.68(0.94)^{* *}$ & $0.44(0.83)^{* *}$ & $0.28(0.59)^{* * *}$ & $<\left.0.00\right|^{a, b}$ \\
\hline \multicolumn{6}{|l|}{ COPD treatment } \\
\hline LAMA & $84.4 \%$ & $92.5 \%$ & $80.8 \%$ & $79.9 \%$ & $0.00 I^{a, b}$ \\
\hline LABA & $82 \%$ & $83.9 \%$ & $80.8 \%$ & $80.9 \%$ & 0.654 \\
\hline ICS & $57 \%$ & $69.3 \%$ & $53.4 \%$ & $48.5 \%$ & $<0.00 I^{a, b}$ \\
\hline Long-term oxygen therapy & $15.4 \%$ & $28.1 \%$ & $13.3 \%$ & $4.6 \%$ & $<\left.0.00\right|^{a, b, c}$ \\
\hline
\end{tabular}

Notes: *Median (interquartile range); ${ }^{*}$ mean (SD); ${ }^{\mathrm{P}}<0.05$ for comparison between the TI group and T2 group. ${ }^{\mathrm{b}} \mathrm{P}<0.05$ for adjusted Bonferroni comparisons between the TI group and T3 group. ${ }^{c} P<0.05$ for adjusted Bonferroni comparisons between the T2 group and T3 group.

Abbreviations: ACO, asthma-COPD overlap; BMI, body mass index; BODEx index, Body mass index, airflow Obstruction, Dyspnea, Exacerbations; CAT, COPD assessment test; CDLM, Capacity of Daily Living during the Morning questionnaire; Dyspnea mMRC, modified Medical Research Council dyspnea scale; GESEPOC, COPD Spanish guideline (Guía Española de la EPOC); ICS, inhaled corticosteroids; LABA, long-acting B2 agonist; LAMA, long-acting muscarinic antagonist; TI, tertile I; T2, tertile 2; T3, tertile 3.

The distribution of the CDLM scores according to clinical phenotypes is shown in Figure 1.

In relation to the COPD severity-related variables, we found a close negative linear relationship between the CAT and CDLM scores (rho $=-0.611$ and $P$-value $<0.001$ ) (Figure 2) and a mild positive linear relationship between $\mathrm{FEV}_{1} \%$ and the CDLM score (rho $=0.214$ and $P$-value $\left.<0.001\right)$ (Figure 3). Figure 4 shows that patients with a lower CDLM score had a higher BODEx index.

\section{Multivariate analysis}

The multinomial regression model showed that patients in the first and second CDLM tertiles with lower CDLM values were significantly older and presented higher CAT and BODEx scores compared to patients in the third tertile. In contrast, patients in the first and second tertiles showed lower $\mathrm{FEV}_{1} \%$ values $(\mathrm{OR}=0.750, P=0.001$ and $\mathrm{OR}=0.860$, respectively; $P=0.001$ ) (Table 2 ).

\section{Other analyses}

\section{Predictive value of the CDLM score compared to a BODEx index $\geq 2$ and a CAT $\geq 10$}

We found an area under the curve (AUC) of the CDLM scores of 0.256 (95\% CI: $0.201-0.305)$ and 0.289 (95\% CI: $0.218-0.358$ ) to detect a patient with BODEx $\geq 2$ or CAT $\geq 10$, respectively. The predictive value of the CDLM score for the 


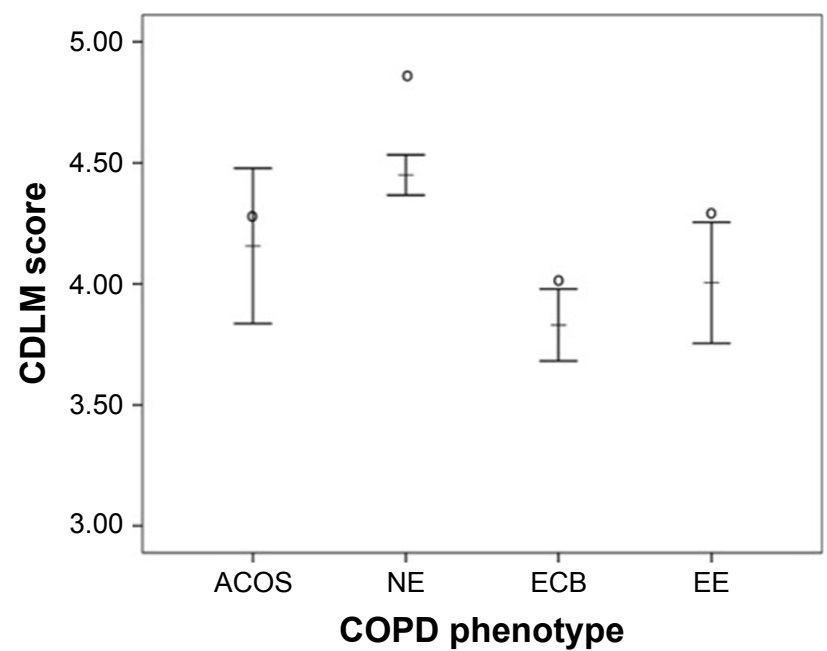

Figure I CDLM score according to clinical COPD phenotype.

Note: Data are expressed as mean $(95 \%$ confidence interval) and median values (circles).

Abbreviations: ACOS, asthma-COPD overlap syndrome; CDLM, Capacity of Daily Living in the Morning questionnaire; ECB, exacerbator with chronic bronchitis; $\mathrm{EE}$, exacerbator with emphysema; NE, non-exacerbator.

combination of the two variables (BODEx $\geq 2$ and $\mathrm{CAT} \geq 10$ ) also showed a low predictive value (AUC $=0.295,95 \% \mathrm{CI}$ : 0.245-0.350). The best predictive cutoff point of CDLM was 3.5 , although this value was not found to be significantly better to identify BODEx $\geq 2$ and CAT $\geq 10$ (AUC $=0.321$, 95\% CI: 0.267-0.401).

\section{Discussion}

\section{Key results}

Our results show that lower CDLM scores (patients in the first and second tertiles) are related to markers of greater COPD severity, in particular with a higher degree of dyspnea and

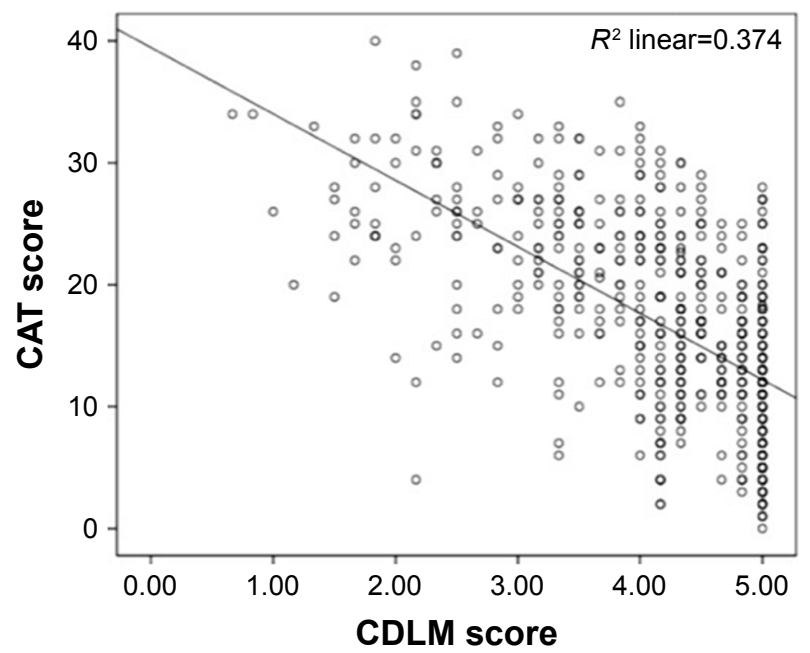

Figure 2 Linear relationship between CAT and CDLM score.

Abbreviations: CAT, COPD assessment test; CDLM, Capacity of Daily Living in the Morning questionnaire.

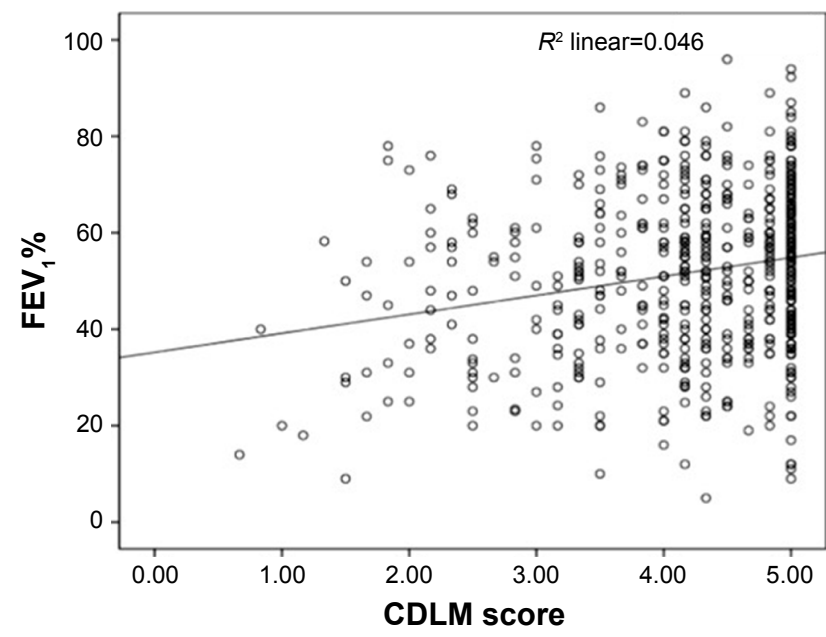

Figure 3 Linear relationship between FEV, (\%) and CDLM score.

Abbreviation: CDLM, Capacity of Daily Living in the Morning questionnaire.

higher CAT and BODEx scores. In addition, patients with lower CDLM scores had greater impairment in lung function tests and a higher rate of exacerbations per year, and more frequently required LTOT. Moreover, patients with lower (worse) CDLM scores were predominantly ECB in contrast to patients with high (better) CDLM scores who were predominantly NE.

\section{Interpretation}

The use of the CDLM questionnaire as a tool to measure the efficacy of different COPD treatments on health status during morning was validated by Partridge et al using the results of secondary analyses of blinded data from two randomized, multicenter, multinational studies. ${ }^{7-10}$ The first

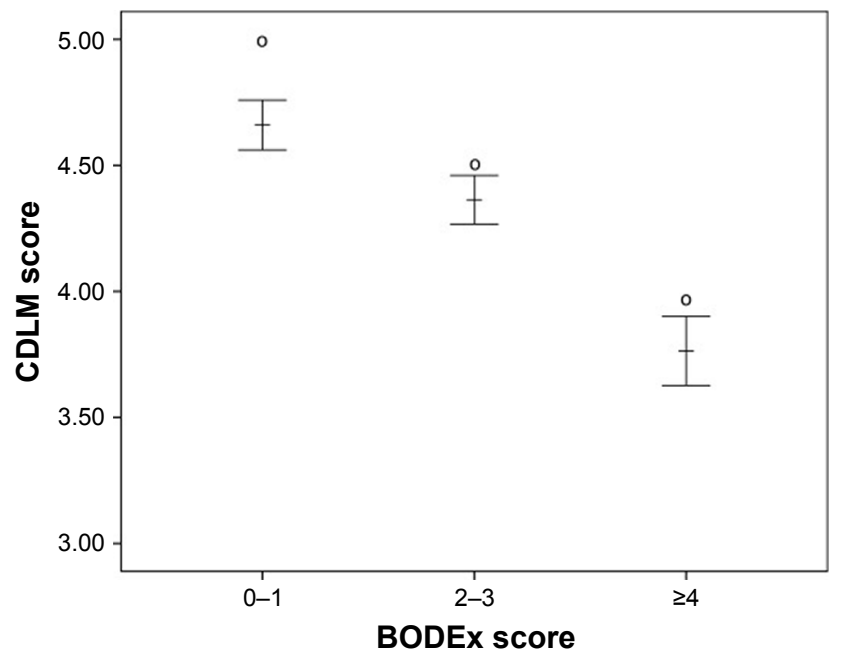

Figure 4 CDLM score according to BODEx index.

Note: Data are expressed as mean ( $95 \%$ confidence interval) and median values (circles).

Abbreviations: BODEx, Body mass index, airflow Obstruction, Dyspnea, Exacerbations; CDLM, Capacity of Daily Living in the Morning questionnaire. 
Table 2 Stepwise multivariate multinomial regression model for CDLM tertiles

\begin{tabular}{|c|c|c|c|c|}
\hline & \multirow[t]{2}{*}{ OR } & \multirow[t]{2}{*}{$P$-value } & \multicolumn{2}{|l|}{ 95\% Cl } \\
\hline & & & $\begin{array}{l}\text { Lower } \\
\text { limit }\end{array}$ & $\begin{array}{l}\text { Upper } \\
\text { limit }\end{array}$ \\
\hline \multicolumn{5}{|l|}{ CDLM tertile I $(<4.17)$} \\
\hline Age (years) & 1.040 & 0.016 & 1.007 & 1.073 \\
\hline Total CAT score & 1.265 & 0.000 & 1.206 & 1.326 \\
\hline BODEx index score & 1.331 & 0.001 & 1.116 & 1.587 \\
\hline Post-bronchodilator $\mathrm{FEV}, \%$ & 0.750 & 0.001 & 0.520 & 0.910 \\
\hline \multicolumn{5}{|l|}{ CDLM tertile 2 (4.17-5.00) } \\
\hline Age (years) & 1.030 & 0.033 & 1.002 & 1.058 \\
\hline Total CAT score & 1.098 & 0.000 & 1.056 & 1.143 \\
\hline BODEx index score & 1.222 & 0.014 & 1.042 & 1.433 \\
\hline Post-bronchodilator FEV,\% & 0.860 & 0.001 & 0.752 & 0.910 \\
\hline
\end{tabular}

Note: The reference category is 3rd tertile of CDLM.

Abbreviations: BODEX index, Body mass index, airflow Obstruction, Dyspnea, Exacerbations; CAT, COPD assessment test; CDLM, Capacity of Daily Living in the Morning questionnaire.

study compared the effect of once-daily tiotropium with a combination of tiotropium plus twice-daily budesonide/ formoterol, and the second study compared the effect of budesonide/formoterol and fluticasone/salmeterol, both in patients with moderate-to-severe COPD. ${ }^{8-10}$ In both the studies, the CDLM questionnaire and the St George's Respiratory Questionnaire (SGRQ) to assess HRQoL were completed before and after the different inhaled treatments. ${ }^{17}$ The CDLM questionnaire showed a moderate-to-high correlation with COPD symptoms, HRQoL (measured by the SGRQ), and the use of rescue medication, but no correlation with lung function parameters such as $\mathrm{FEV}_{1}$, and it did not distinguish between different levels of disease severity. In addition, the authors calculated the MCID of the CDLM scores and found that a change in the CDLM score of 0.20 corresponded to a change of four units in the SGRQ score. ${ }^{7}$

In contrast to the previous trials, we analyzed CDLM scores and their relationship with clinical variables of COPD severity, instead of analyzing changes in scores induced by treatment. Our results showed that higher CAT and BODEx scores and a lower $\mathrm{FEV}_{1} \%$ were independently related to lower CDLM scores. In addition, we found a ceiling effect, observing that $72.5 \%$ had a score higher than 4.00 and one-third of our population obtained the maximal score of 5.00. No floor effect was observed and the lowest score reported was 0.67. The CDLM questionnaire agglomerates most of the patients in the upper limit and, thus, does not discriminate well between different levels of COPD severity. Establishing a convergent point between CDLM scores and high BODEx and CAT scores was not possible, and therefore, we could not determine an arbitrary cutoff to differentiate high impact of morning symptoms from low impact.

Other questionnaires have been used to assess morning symptoms, such as the Early Morning Symptoms of COPD Instrument (EMSCI), which evaluates three concepts in COPD patients: the occurrence and impact of morning symptoms and the use of rescue medication. ${ }^{18}$ In a recent international study including 734 patients with COPD, the EMSCI identified a group of 147 (20\%) patients with severe morning symptoms. These patients were mostly women with more severe COPD in terms of lung function and BODEx, and who were more inactive and presented more exacerbations. ${ }^{19}$

Another multicenter study used a Nighttime, Morning and Daytime Symptoms of COPD questionnaire, developed by the study sponsor, in order to assess the impact of symptoms in COPD patients. This questionnaire divides the day into three periods and asks patients about the frequency and severity of respiratory symptoms during each period. A significant relationship was observed between early morning and daytime symptoms and the severity of airflow limitation and in general, patients with symptoms during any period of the day had worse outcomes, including health status, anxiety, and depression levels. ${ }^{20}$

Moreover, in a recent study, physical activity carried out along the day was assessed according to morning symptoms. ${ }^{21}$ Morning symptoms were evaluated with the PRO-Morning COPD Symptoms Questionnaire which consists of six questions about dyspnea, cough, sputum production, wheezing, chest tightness, and limitations in the morning, and the severity of these symptoms is rated with a Likert scale from 0 to 10 points ( 0 for no symptoms and 10 for the worst symptoms). ${ }^{22}$ A significant difference was observed in the physical activity during the morning and afternoon between patients with severe and few morning symptoms: patients with high morning symptom scores took fewer steps throughout the day, showing an association between morning symptoms and lower physical activity. ${ }^{21}$

The development of these tools to investigate morning symptoms highlights the importance of this part of the day for COPD patients. ${ }^{6,23}$ Indeed, it is likely that the development of pharmacological and non-pharmacological interventions could improve the health status of these patients in the morning. The use of validated questionnaires may help researchers and clinicians to identify this problem 
and compare different strategies to improve the HRQoL of patients with COPD. ${ }^{24}$

\section{Limitations of the study}

Taking into account the cross-sectional design of this study, we were unable to analyze the direction of the associations observed, and hence, further prospective studies are needed. Our population included predominantly men, and all patients were smokers or former smokers; therefore, our results may not be extrapolated to the general population.

The main strengths of this study are the large sample of COPD patients included with a large range of disease severity and different clinical settings.

\section{Conclusion}

The highest impact in morning symptoms measured by the CDLM questionnaire was associated with markers of COPD severity, such as worse lung function, a higher rate of exacerbations, and a greater number of symptoms. Due to the ceiling effect of this questionnaire, it may not be useful in clinical practice to discriminate between the high or low impact of morning symptoms, and thus, it would be more adequate for the evaluation of response to different treatment options in clinical trials.

\section{Acknowledgments}

The authors would like to thank the investigators and the centers that participated in the FENEPOC study. The FENEPOC study was sponsored by the laboratory NOVARTIS Farmacéutica, SA.

\section{Disclosure}

Miriam Barrecheguren has received speaker fees from Grifols, Menarini, and GSK; and consultancy fees from Novartis and Gebro Pharma. Myriam Calle has received speaker fees from Boehringer Ingelheim, AstraZeneca, GlaxoSmithKline, Menarini, and Novartis. Ricard Casamor is a full-time employee of Novartis-Pharmaceuticals. Marc Miravitlles has received honoraria from Novartis for conducting the FENEPOC study; speaker fees from Boehringer Ingelheim, Chiesi, Cipla, Menarini, Rovi, Bial, Grifols, and Novartis; consultancy fees from Boehringer Ingelheim, Chiesi, GlaxoSmithKline, Bial, Gebro Pharma, CSL Behring, Laboratorios Esteve, Mereo Biopharma, Verona Pharma, pH Pharma, Novartis, and Grifols; and research grants from GlaxoSmithKline and Grifols, outside the submitted work. The authors report no other conflicts of interest in this work.

\section{References}

1. Decramer M, Janssens W, Miravitlles M. Chronic obstructive pulmonary disease. Lancet. 2012;379(9823):1341-1351.

2. Borsboom GJ, van Pelt W, van Houwelingen HC, van Vianen BG, Schouten JP, Quanjer PH. Diurnal variation in lung function in subgroups from two Dutch populations. Am J Respir Crit Care Med. 1999;159(4 Pt 1):1163-1171.

3. Calverley PM, Lee A, Towse L, van Noord J, Witek TJ, Kelsen S. Effect of tiotropium bromide on circadian variation in airflow limitation in chronic obstructive pulmonary disease. Thorax. 2003;58(10):855-860.

4. McCarley C, Hanneman SK, Padhye N, Smolensky MH. A pilot home study of temporal variations of symptoms in chronic obstructive lung disease. Biol Res Nurs. 2007;9(1):8-20.

5. Postma DS, Koëter GH, vd Mark TW, Reig RP, Sluiter HJ. The effects of oral slow-release terbutaline on the circadian variation in spirometry and arterial blood gas levels in patients with chronic airflow obstruction. Chest. 1985;87(5):653-657.

6. Partridge MR, Karlsson N, Small IR. Patient insight into the impact of chronic obstructive pulmonary disease in the morning: an internet survey. Curr Med Res Opin. 2009;25(8):2043-2048.

7. Partridge MR, Miravitlles M, Ståhl E, Karlsson N, Svensson K, Welte T. Development and validation of the Capacity of Daily Living during the Morning questionnaire and the Global Chest Symptoms Questionnaire in COPD. Eur Respir J. 2010;36(1):96-104.

8. Welte T, Miravitlles M, Hernandez P, et al. Efficacy and tolerability of budesonide/formoterol added to tiotropium in patients with chronic obstructive pulmonary disease. Am J Respir Crit Care Med. 2009;180(8): 741-750.

9. Welte T. Optimising treatment for COPD - new strategies for combination therapy. Int J Clin Pract. 2009;63(8):1136-1149.

10. Partridge MR, Schuermann W, Beckman O, Persson T, Polanowski T. Effect on lung function and morning activities of budesonide/formoterol versus salmeterol/fluticasone in patients with COPD. Ther Adv Respir Dis. 2009;3(4):1-11.

11. Calle Rubio M, Casamor R, Miravitlles M. Identification and distribution of COPD phenotypes in clinical practice according to Spanish COPD Guidelines: the FENEPOC study. Int J Chron Obstruct Pulmon Dis. 2017;12:2373-2383.

12. Bestall JC, Paul EA, Garrod R, Garnham R, Jones PW, Wedzicha JA. Usefulness of the Medical Research Council (MRC) dyspnoea scale as a measure of disability in patients with chronic obstructive pulmonary disease. Thorax. 1999;54(7):581-586.

13. Soler-Cataluña JJ, Martínez-García MA, Sánchez LS, Tordera MP, Sánchez PR. Severe exacerbations and BODE index: two independent risk factors for death in male COPD patients. Respir Med. 2009; 103(5):692-699.

14. Miravitlles M, Soler-Cataluña JJ, Calle M, et al. Spanish Guidelines for Management of Chronic Obstructive Pulmonary Disease (GesEPOC) 2017. Pharmacological Treatment of Stable Phase. Arch Bronconeumol. 2017;53(6):324-335. English, Spanish.

15. Soler-Cataluña JJ, Cosío B, Izquierdo JL, et al. Consensus document on the overlap phenotype COPD-asthma in COPD. Arch Bronconeumol. 2012;48(9):331-337. English, Spanish.

16. Jones PW, Harding G, Berry P, Wiklund I, Chen WH, Kline Leidy N. Development and first validation of the COPD Assessment Test. Eur Respir J. 2009;34(3):648-654.

17. Jones PW, Quirk FH, Baveystock CM. A self-complete measure of health status for chronic airflow limitation. Am Rev Respir Dis. 1992; 145(6):1321-1327.

18. Eremenco S, Albuquerque P, Arnold BJ, Trundell D, Hareendran A. Translation and linguistic validation of two COPD symptom diaries (NiCSI and EMSCI) for use in 14 countries. Value Health. 2014;17(7):A600.

19. Miravitlles M, Menezes A, López Varela MV, et al. Prevalence and impact of respiratory symptoms in a population of patients with COPD in Latin America: The LASSYC observational study. Respir Med. 2018;134:62-69. 
20. Miravitlles M, Worth H, Soler Cataluña JJ, et al. Observational study to characterise 24-hour COPD symptoms and their relationship with patient-reported outcomes: results from the ASSESS study. Respir Res. 2014; $15: 122$.

21. van Buul AR, Kasteleyn MJ, Chavannes NH, Taube C. Physical activity in the morning and afternoon is lower in patients with chronic obstructive pulmonary disease with morning symptoms. Respir Res. 2018;19(1):49.

22. Marin JM, Beeh KM, Clemens A, et al. Early bronchodilator action of glycopyrronium versus tiotropium in moderate-to-severe COPD patients: a cross-over blinded randomized study (Symptoms and Pulmonary function in the moRnING). Int J Chron Obstruct Pulmon Dis. 2016;11:1425-1434.
23. Roche N, Chavannes NH, Miravitlles M. COPD symptoms in the morning: impact, evaluation and management. Respir Res. 2013;14:112.

24. Jones P, Miravitlles M, van der Molen T. Beyond FEV1 in COPD - a review of patient-reported outcomes and their measurement using a new generation of instruments. Int J Chron Obst Pulm Dis. 2012;7: $697-709$.

\section{Publish your work in this journal}

The International Journal of COPD is an international, peer-reviewed journal of therapeutics and pharmacology focusing on concise rapid reporting of clinical studies and reviews in COPD. Special focus is given to the pathophysiological processes underlying the disease, intervention programs, patient focused education, and self management protocols.

\section{Dovepress}

This journal is indexed on PubMed Central, MedLine and CAS. The manuscript management system is completely online and includes a very quick and fair peer-review system, which is all easy to use. Visit $\mathrm{http}: / / \mathrm{www}$.dovepress.com/testimonials.php to read real quotes from published authors. 